СТАТЬИ

УДК 712.256
АНАЛИЗ СОСТОЯНИЯ БЛАГОУСТРОЙСТВА И ОЗЕЛЕНЕНИЯ ДЕТСКИХ ИГРОВЫХ ПЛОЩАДОК В ГОРОДЕ МОСКВЕ

\author{
Довганюк А.И. \\ ФГБОУ ВО «Российский государственный аграрный университет РГАУ- МСХА \\ имени К.А. Тимирязева», Москва, е-mail: alexadov@mail.ru
}

\begin{abstract}
Работа посвящена анализу организации среды детских игровых площадок в г. Москве. В соответствии с действующими нормативными документами детские игровые площадки должны находиться в жилой застройке в непосредственной близости от жилых домов. Комплекс имеющихся нормативно-правовых документов, непосредственно связанный с организацией территории детской игровой площадки, в настоящее время представляет собой недостаточно разработанный и недостаточно согласованный между собой комплекс документов. В работе предпринята попытка проанализировать комплекс нормативно-правовых документов и разработать методику оценки, основанную на действующих документах, которая была бы способна всесторонне описать имеющиеся детские игровые площадки. Предложена шкала, состоящая из общих требований по расположению площадки, а также из требований, предъявляемых к оборудованию. Каждый из 12 предложенных пунктов имеет градацию от 0 (полностью не соответствует) до 2 (полностью соответствует). В соответствии с предложенной шкалой был проведен анализ 58 детских игровых площадок, расположенных в г. Москве. Выявлены несоответствия в организации территории (размеров площадки, расположении площадок относительно жилых домов, парковочных территорий, деревьев и т.д.), а также в наполнении ее элементами благоустройства и озеленения. Особенно неблагоприятная ситуация отмечена с озеленением детских игровых площадок. Боле чем на $80 \%$ детских игровых площадках отсутствует непосредственно связанное с площадкой озеленение. Отмечена важность озеленения площадок, особенно для возрастной группы 1-3 года в связи с особым сенсорным типом игры, реализуемой этой возрастной группой детей. Озеленение будет способствовать развитию образного мышления и формированию навыков общения с растительным миром. Сделан вывод об отсутствии единого стилевого и композиционного замысла в формировании единого образа детской площадки.
\end{abstract}

Ключевые слова: детская игровая площадка, озеленение детских площадок, благоустройство детских площадок, игровое оборудование, виды игры, пространственная организация детских площадок

\title{
ANALYSIS OF THE STATE OF LANDSCAPING AND LANDSCAPING OF CHILDREN'S PLAYGROUNDS IN MOSCOW
}

\section{Dovganyuk A.I.}

Russian State Agrarian University - Moscow Timiryazev Agricultural Academy, Moscow,e-mail: alexadov@mail.ru

\begin{abstract}
The work is devoted to the analysis of the organization of the environment of children's playgrounds in Moscow. In accordance with the current regulations, children's playgrounds should be located in residential buildings in the immediate vicinity of residential buildings. The complex of existing legal documents directly related to the organization of the territory of the children's playground is currently not sufficiently developed and coordinated with each other set of documents. The paper attempts to analyze a set of regulatory and legal documents and develop an assessment methodology based on existing documents that would be able to comprehensively describe the existing children's playgrounds. A scale consisting of the general requirements for the location of the site, as well as the requirements for the equipment, is proposed. Each of the 12 suggested points has a gradation from 0 (completely does not correspond to) up to 2 (fully compliant). In accordance with the proposed scale, an analysis of 58 children's playgrounds located in Moscow was carried out. Inconsistencies were found in the organization of the territory (the size of the site, the location of the sites relative to residential buildings, parking areas, trees, etc.), as well as in filling it with elements of landscaping and landscaping. A particularly unfavorable situation was noted with the landscaping of children's playgrounds. More than $80 \%$ of children's playgrounds do not have landscaping directly related to the playground. The importance of landscaping of playgrounds is noted, especially for the age group of 1-3 years in connection with the special sensory type of game implemented by this age group of children. Gardening will contribute to the development of imaginative thinking and the formation of communication skills with the plant world. It is concluded that there is no single stylistic and compositional idea in the formation of a single image of the playground.
\end{abstract}

Keywords: children's playground, landscaping of playgrounds, landscaping of playgrounds, play equipment, types of games, spatial organization of playgrounds

Игра - один из важнейших видов деятельности для детей. Через игру ребенок познает мир и учится взаимодействовать как с окружающими его предметами и объектами, так и с людьми. Именно поэтому окружающий ребенка мир должен быть комфортным, устойчивым и безопасным [1]. Организация комфортной, устойчивой и безопасной среды (КУБ-среды) для ребенка на всех объектах ландшафтной архитектуры, с которыми ребенок взаимодействует, представляет интерес и нема- 
лую сложность для любого ландшафтного архитектора. Ландшафтный архитектор работает со средой, проектируя и реализуя элементы благоустройства и озеленения для каждой конкретной территории. Детская игровая площадка - особый мир ребенка, организация предметно-пространственной среды этого мира - сложная и интересная задача. Организация этой среды должна не только отвечать задачам оздоровления и обучения ребенка, но и предполагать игровую составляющую.

В настоящий момент в России реализуется несколько программ по созданию комфортной среды, улучшению условий озеленения и благоустройства ряда городских территорий, в частности федеральный проект «Формирование комфортной городской среды», паспорт которого утвержден протоколом заседания проектного комитета по национальному проекту «Жилье и городская среда» от 21 декабря 2018 г. № 3. Попадают под эту программу и детские игровые площадки. Однако отсутствие методических указаний по формированию комфортной, устойчивой и безопасной среды для ребенка на детских игровых площадках самым негативным образом сказывается на результате. Имеющиеся нормативно-правовые документы зачастую противоречат друг другу в деталях, а предлагаемые там элементы благоустройства и озеленения не решают основную задачу - создания $К У Б$-среды для ребенка. Ландшафтные архитекторы формируют предметно-пространственную среду исходя из сиюминутных предложений по материалам и элементам озеленения и благоустройства. Проведенные нами ранее исследования показали, что имеющееся детское игровое оборудование не интересно ребенку, более $30 \%$ детей используют его не по назначению [2]. Социологические исследования показали, что дети видят свой игровой мир - территорию детской игровой площадки совершенно по-другому. Ее предметно-пространственное наполнение должно включать иные игровые комплексы.

Важно учитывать возрастные изменения в игровых пристрастиях ребенка $[3,4]$. Каждому возрасту ребенка соответствует свой тип игры. Выделяют как сенсорные и сенсорно-моторные игры с минимальным взаимодействием между детьми, так и спортивные групповые соревнования. Таким образом, озеленение и благоустройство детской игровой площадки должно соответствовать возрастным особенностям взаимодействия ребенка с элементами среды.
Цель исследования: провести анализ благоустройства и озеленения детских игровых площадок, расположенных в жилых районах г. Москвы.

Задачи работы предполагают критический анализ действующих нормативно-правовых документов, разработку методики оценки соответствия предметно-пространственной среды детской игровой площадки действующим нормативам, а также проведение анализа среды и разработку предложений по формированию на детских игровых площадках $К У Б$-среды для ребенка.

\section{Материалы и методы исследования}

В настоящее время нормативно-правовое обеспечение благоустройства и озеленения детских игровых площадок связано с группой национальных ГОСТов, принятых в 2012-2013 гг., и методическими рекомендациями 2019 г. Кроме того, действуют отдельные нормативно-правовые документы регионального (московского) уровня. Необходимо выделить ГОСТ Р 52301-2013, ТСН 30-307-2002 г. Москвы (МГСН 1.02-02), письмо Минрегиона России от 14.12.2010 № 42053-ИБ/14, СанПиН 2.2.1/2.1.1.1200-03 и Приказ Минстроя России № 897 / приказ Минспорта России № 1128 от 27.12.2019. На основе анализа указанных нормативных документов предложена схема анализа предметно-пространственной среды детских игровых площадок.

Было обследовано 58 детских игровых площадок (рис. 1). Анализируемые детские игровые площадки расположены в Северном административном округе г. Москвы.

\section{Результаты исследования и их обсуждение}

Приведенные выше нормативно-правовые документы предусматривают несколько обязательных условий по размещению детской игровой площадки на территории и наполнению её элементами благоустройства. Необходимо предусмотреть корректное расстояние от окон жилого дома (ТCH 30-307-2002, Приложение к письму Минрегиона России от 14.12.2010 № 42053-ИБ/14) и парковки (СанПиН 2.2.1/2.1.1.1200-03, табл. 4.4.1) до границ детской площадки [57]. Площадь детской игровой площадки должна соответствовать норме на одного жителя $\left(0,5-0,7 \mathrm{M}^{2}\right)$ и средним рекомендуемым размерам площадок в зависимости от возрастной группы детей, предусмотренным нормативно-правовыми документами $[5,6]$. 


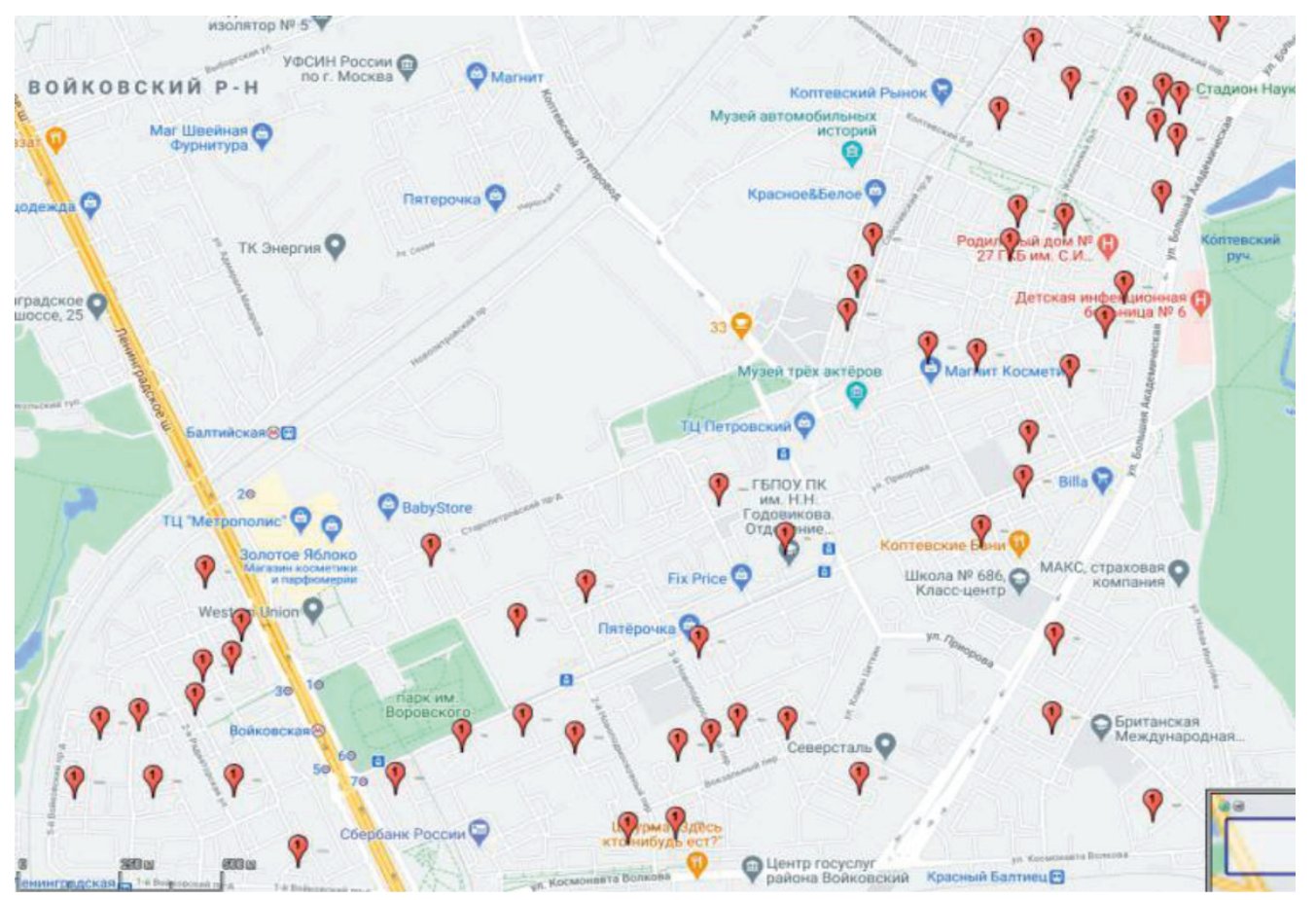

Расположение исследуемых детских игровых площчадок

Утвержденные нормативы предусматривают требования к инсоляции детской игровой площадки (не менее 5 ч светового дня), расстоянию до деревьев (деревья с восточной и северной сторон площадки должны высаживаться не ближе 3 м, а с южной и западной - не ближе 1 м от края площадки до оси дерева). Обязательными элементами благоустройства являются «мягкие» виды покрытия, наличие элементов сопряжения поверхности площадки с газоном в виде бортовых камней со скошенными или закругленными краями, наличие скамей и урн на территории площадки, функционального освещения на высоте не менее 2,5 м. ГОСТ Р 52301-2013 предусматривает размещение на детской игровой площадке информационного стенда (доски) с перечнем и назначением детского игрового оборудования, телефонами экстренных служб и правилами эксплуатации площадки [8]. Bce указанные выше требования в полном объеме нашли отражение в утвержденных в 2019 г. методических рекомендациях по благоустройству общественных и дворовых территорий средствами спортивной и детской игровой инфраструктуры [9].

Обязательным элементом является озеленение территории, однако требования к подбору растений для озеленения ограничены двумя пунктами: не допускается применение растений с колючками на площадках дошкольного типа и растений с ядовитыми плодами на площадках всех видов. Не указаны рекомендуемые формы организации декоративных посадок.

C учетом указанных требований нормативно-правовых документов, предъявляемых к обустройству детских игровых площадок, была составлена балльная схема описания (анкета), предусматривающая максимальное количество баллов в случае полного удовлетворения требованиям нормативных документов территории и элементов площадки и штрафные санкции за частичное выполнение или невыполнение этих требований (табл. 1).

В соответствии с разработанной анкетой была проведена оценка состояния благоустройства и озеленения территории 58 детских игровых площадок (табл. 2).

По результатам оценки состояния детских игровых площадок можно выделить основные негативные моменты и тенденции, наблюдаемые в Москве. Детские игровые площадки в существующих жилых районах сделаны формально. При этом расположение детской игровой площадки относительно жилого дома и ее площадь 
в большинстве случаев соответствуют регламенту. Однако прочие показатели очень далеки от идеала. Особенно в негативную сторону выделяется ситуация с расположе- нием площадок относительно санкционированных и несанкционированных парковок. Только в 20\% случаев выдерживаются требуемые расстояния.

Анкета анализа детской площадки (методика оценки)

Таблица 1

\begin{tabular}{|c|c|c|}
\hline Наименование показателя & Критерий оценки & Балл \\
\hline \multicolumn{3}{|c|}{ 1. Общие требования } \\
\hline $\begin{array}{l}\text { 1.1. Соответствие расстояния от гра- } \\
\text { ницы площадки до окон жилого дома } \\
\text { требованиям регламентирующих до- } \\
\text { кументов }\end{array}$ & $\begin{array}{l}2 \text { балла - в соответствии с ТСН 30-307-2002; } \\
1 \text { балл - нарушение не более } 50 \% \text { расстояния; } \\
0 \text { баллов - нарушение более } 50 \% \text { расстояния }\end{array}$ & \\
\hline $\begin{array}{l}\text { 1.2. Соответствие площади детской } \\
\text { площадки требованиям регламенти- } \\
\text { рующих документов }\end{array}$ & $\begin{array}{l}2 \text { балла - в соответствии с ТСН } 30-307-2002-0,5-0,7 \text { м }^{2} \\
\text { на одного жителя; } \\
1 \text { балл - нарушение не более } 50 \%\left(0,26-0,49 \mathrm{M}^{2}\right) ; \\
0 \text { баллов - нарушение более } 50 \%\left(<0,25 \mathrm{~m}^{2}\right)\end{array}$ & \\
\hline $\begin{array}{l}\text { 1.3. Соответствие инсоляционного } \\
\text { режима требованиям регламентиру- } \\
\text { ющих документов }\end{array}$ & $\begin{array}{l}2 \text { балла - в соответствии с ТСН 30-307-2002 - более } 5 \text { ч } \\
\text { в день; } \\
1 \text { балл - нарушение не более } 50 \% \text { (2,5 ч в день); } \\
0 \text { баллов - нарушение более } 50 \% \text { (<2,4 ч в день })\end{array}$ & \\
\hline $\begin{array}{l}\text { 1.4. Соответствие расстояния от дет- } \\
\text { ской игровой площадки до парковки }\end{array}$ & $\begin{array}{l}2 \text { балла - в соответствии с СанПиН; } \\
1 \text { балл - нормы нарушает несанкционированная парковка } \\
\text { (без разметки); } \\
0 \text { баллов - не соответствует СанПиН }\end{array}$ & \\
\hline $\begin{array}{l}\text { 1.5. Соответствие расстояния от пло- } \\
\text { щадки до деревьев требованиям ре- } \\
\text { гламентирующих документов }\end{array}$ & $\begin{array}{l}2 \text { балла - в соответствии с ТСН 30-307-2002; } \\
1 \text { балл - деревья присутствуют рядом с территорией, ближе } \\
\text { допустимых нормативов; } \\
0 \text { баллов - деревья присутствуют на территории площадки }\end{array}$ & \\
\hline \multicolumn{3}{|c|}{ 2. Требования по оборудованию } \\
\hline 2.1. Наличие информационного стенда & $\begin{array}{l}2 \text { балла - в соответствии с нормативом (наличие и содер- } \\
\text { жание); } \\
1 \text { балл - имеется, но не соответствует нормативу; } \\
0 \text { баллов - отсутствует } \\
\end{array}$ & \\
\hline $\begin{array}{l}\text { 2.2. Соответствие типа покрытия } \\
\text { площадки требованиям регламенти- } \\
\text { рующих документов }\end{array}$ & $\begin{array}{l}2 \text { балла - в соответствии с нормативом (наличие и содер- } \\
\text { жание); } \\
1 \text { балл - имеется, но не соответствует нормативу (поврежде- } \\
\text { ния на большой площади); } \\
0 \text { баллов - отсутствует }\end{array}$ & \\
\hline $\begin{array}{l}\text { 2.3. Соответствие элементов сопря- } \\
\text { жения поверхности площадки с га- } \\
\text { зоном требованиям регламентирую- } \\
\text { щих документов }\end{array}$ & $\begin{array}{l}2 \text { балла - в соответствии с ТСН 30-307-2002; } \\
1 \text { балл - в соответствии с ТСН 30-307-2002, но повреждены; } \\
0 \text { баллов - не соответствуют ТСН 30-307-2002 }\end{array}$ & \\
\hline $\begin{array}{l}\text { 2.4. Наличие озеленения и коррект- } \\
\text { ность используемых растений }\end{array}$ & $\begin{array}{l}2 \text { балла - в соответствии с ТСН 30-307-2002; } \\
1 \text { балл - отсутствует; } \\
0 \text { баллов - присутствуют колючие и ядовитые растения }\end{array}$ & \\
\hline 2.5. Состояние игрового оборудования & $\begin{array}{l}2 \text { балла - состояние отличное без повреждений; } \\
1 \text { балл - состояние хорошее и удовлетворительное, имеются } \\
\text { повреждения, не влияющие на безопасность эксплуатации; } \\
0 \text { баллов - состояние неудовлетворительное }\end{array}$ & \\
\hline $\begin{array}{l}\text { 2.6. Наличие и соответствие требова- } \\
\text { ниям регламентирующих докумен- } \\
\text { тов скамей и урн }\end{array}$ & $\begin{array}{l}2 \text { балла - имеются в состоянии, позволяющем нормальную } \\
\text { эксплуатацию, установлены на твердом покрытии; } \\
1 \text { балл - имеются в состоянии, позволяющем нормальную } \\
\text { эксплуатацию, установлены на мягком покрытии; } \\
0 \text { баллов - отсутствуют или имеются в состоянии, не по- } \\
\text { зволяющем нормальную эксплуатацию } \\
\end{array}$ & \\
\hline $\begin{array}{l}\text { 2.7. Наличие и соответствие требова- } \\
\text { ниям регламентирующих докумен-- } \\
\text { тов элементов освещения }\end{array}$ & $\begin{array}{l}2 \text { балла - имеется, в соответствии с ТСН 30-307-2002; } \\
1 \text { балл - имеется, не соответствует ТСН 30-307-2002; } \\
0 \text { баллов - отсутствует }\end{array}$ & \\
\hline
\end{tabular}
тов элементов освещения 
Балльная оценка состояния благоустройства и озеленения территорий детских игровых площадок

\begin{tabular}{|l|c|}
\hline \multicolumn{1}{|c|}{ Показатель } & $\begin{array}{c}\text { Средний балл } \\
(0-\text { мин, } \\
2-\text { макс) }\end{array}$ \\
\hline $\begin{array}{l}\text { 1.1. Соответствие расстояния от границы площадки до окон жилого дома требованиям } \\
\text { регламентирующих документов }\end{array}$ & 1,59 \\
\hline 1.2. Соответствие площади детской площадки требованиям регламентирующих документов & 1,45 \\
\hline 1.3. Соответствие инсоляционного режима требованиям регламентирующих документов & 1,16 \\
\hline 1.4. Соответствие расстояния от детской игровой площадки до парковки & 0,43 \\
\hline $\begin{array}{l}\text { 1.5. Соответствие расстояния от площадки до деревьев требованиям регламентирующих } \\
\text { документов }\end{array}$ & 0,69 \\
\hline 2.1. Наличие информационного стенда & 1,10 \\
\hline 2.2. Соответствие типа покрытия площадки требованиям регламентирующих документов & 1,41 \\
\hline $\begin{array}{l}\text { 2.3. Соответствие элементов сопряжения поверхности площадки с газоном требованиям } \\
\text { регламентирующих документов }\end{array}$ & 0,81 \\
\hline 2.4. Наличие озеленения и корректность используемых растений & 0,24 \\
\hline 2.5. Состояние игрового оборудования & 1,21 \\
\hline 2.6. Наличие и соответствие требованиям регламентирующих документов скамей и урн & 1,05 \\
\hline $\begin{array}{l}\text { 2.7. Наличие и соответствие требованиям регламентирующих документов элементов ос- } \\
\text { вещения }\end{array}$ & 0,86 \\
\hline
\end{tabular}

Лучше обстоят дела с элементами благоустройства. Информационный стенд, покрытия площадок и элементы сопряжения поверхности площадки и газона, скамьи и урны более чем в $50 \%$ случаев удовлетворяют требованиям нормативно-правовых документов. Однако наполнение детских площадок игровым оборудованием и его взаимное расположение вызывает большие вопросы. Например, на ряде обследуемых территорий качалки, предназначенные для сенсорно-моторной игры детей возрастной категории 1-3 года, располагаются в непосредственной близости от детских игровых комплексов, которые предназначены для ролевых групповых взаимодействий детей 4-7 лет. Более того, нередко игровое оборудование, предназначенное для младших детей, располагается на транзитных путях движения взрослых по территории площадки или путях игровых перемещений более взрослых детей.

Состояние озеленения детских игровых площадок удручающее. Практически все детские игровые площадки «вписаны» в существующие условия озеленения территорий жилых дворов. Данное озеленение в подавляющем большинстве случаев сделано жителями без учета норм расположения растений относительно жилых домов и строений. Поэтому «вписать» площадку с соблюдением норм расположения деревьев оказалось практически невозможно.
Взрослые деревья расположены в пределах детской игровой площадки (более $60 \%$ площадок), что увеличивает опасность получения травмы ребенком во время активных игр, а также затрудняет уход за территорией площадки в осенне-зимний период. Специализированное озеленение отсутствует практически на всех площадках. Важно указать важную роль озеленения и работы с растениями для детей возрастной категории 1-3 года. В период сенсорной и сенсорно-моторной игры ребенок должен познакомиться с разнообразными элементами живой природы, которые могут дать только растения.

\section{Заключение}

Наличие большого количества нормативов, которые нередко не уточняют друг друга, а наоборот, включают в себя взаимоисключающие тезисы, привело к деградации понятия детская игровая площадка в существующих жилых районах мегаполиса. Отсутствие единого стилевого и композиционного замысла привело к появлению в пределах жилой застройки безликих детских игровых площадок, единственная роль которых заключается в доведении нормы площади города под детскими игровыми площадками до рекомендуемой. Благоустройство детских игровых площадок не в полной мере соответствует нормативным показателям. Обоснованное компо- 
зиционными принципами формирование озеленения на детских игровых площадках не выявлено.

\section{Список литературы / References}

1. Довганюк А.И. Ландшафт ребенка // Доклады ТСХА: сборник статей. М.: Издательство РГАУ - МСХА. 2021. Вып. 293. С. 34-36.

Dovganyuk A. I. Landscape of the child // Doklady TSKHA : sbornik statej. M.: Izdatel'stvo RGAU - MSKHA. 2021. Vyp. 293. P. 34-36 (in Russian).

2. Егорова К.В., Довганюк А.И. Рекомендации по созданию развивающих площадок для детей раннего и дошкольного возраста // Вестник ландшафтной архитектуры. М.: Редакция журнала МЭСХ. 2013. С. 13-16.

Egorova K.V., Dovganyuk A.I. Recommendations for creating educational platforms for children of early and preschool age // Vestnik landshaftnoj arhitektury. M.: MESKH. 2013. P. 13-16 (in Russian).

3. Дьяченко О.М., Лаврентьева Т.В. Психологические особенности развития дошкольников. М.: Эксмо, 2009. 176 с

Dyachenko O.M., Lavrentieva T.V. Psychological features of preschool children 's development. M.: Eksmo, 2009. 176 p. (in Russian)

4. Фадина Н.В., Довганюк А.И. К вопросу о соответствии детского игрового оборудования возрастной категории ребенка (на примере детских площадок района Марьино г. Москвы) // Вестник ландшафтной архитектуры. М.: МЭСХ, 2019. Вып. 19. С. 76-81.

Fadina N.V., Dovganyuk A.I. On the question of the compliance of children's play equipment with the age category of a child (on the example of playgrounds in the Maryino district of Moscow) // Vestnik landshaftnoj arhitektury. M.: MESKH, 2019. Vyp. 19. P. 76-81 (in Russian).

5. ТСН 30-307-2002 г. Москвы (МГСН 1.02-02) Нормы и правила проектирования комплексного благоустройства на территории города Москвы. [Электронный ресурс] URL: http://docs.cntd.ru/document/1200029835 (дата обращения: 28.03.2021)
TSN 30-307-2002 Moskvy (MGSN 1.02-02) Norms and rules for designing complex landscaping on the territory of the city of Moscow. [Electronic resource]. URL: http://docs.cntd. $\mathrm{ru} /$ document/1200029835 (date of the application: 28.03.2021) (in Russian).

6. Об утверждении Предложений по благоустройству придомовой территории в части детской спортивноигровой инфраструктуры (письмо Минрегиона России от 14.12.2010 № 42053-ИБ/14). [Электронный ресурс] URL: https://legalacts.ru/doc/pismo-minregiona-rossii-ot-14122010n-42053-ib14/ (дата обращения: 20.04.2021).

On the approval of Proposals for the improvement of the house territory in terms of children's sports and game infrastructure (letter from the Ministry of Regional Development of Russia from 14.12.2010 N 42053-ИБ/14). [Electronic resource]. URL: https://legalacts.ru/doc/pismo-minregiona-rossii-ot14122010-n-42053-ib14/ (date of the application: 20.04.2021) (in Russian).

7. СанПиН 2.2.1/2.1.1.1200-03. Санитарно-защитные зоны и санитарная классификация предприятий, сооружений и иных объектов. [Электронный ресурс]. URL: https://docs. cntd.ru/document/902065388 (дата обращения: 28.03.2021).

SanPiN 2.2.1/2.1.1.1200-03. Sanitary protection zones and sanitary classification of enterprises, structures and other objects. [Electronic resource]. URL: https://docs.cntd.ru/ document/902065388 (date of the application: 20.04.2021) (in Russian).

8. ГОСТ Р 52301-2013 Оборудование и покрытия детских игровых площадок. Безопасность при эксплуатации. Общие требования. [Электронный ресурс]. URL: https://docs. cntd.ru/document/1200105947 (дата обращения: 20.04.2021).

9. Методические рекомендации по благоустройству общественных и дворовых территорий средствами спортивной и детской игровой инфраструктуры. [Электронный pecypc]. URL: https://ppt.ru/docs/prikaz/minstroy/n-897pr-227183 (дата обращения: 20.04.2021).

Methodological recommendations for the improvement of public and courtyard territories by means of sports and children's play infrastructure. [Electronic resource]. URL: https://ppt.ru/ docs/prikaz/minstroy/n-897-pr-227183 (date of the application: 20.04.2021) (in Russian). 